INTERNATIONAL HIGHER EDUCATION - NUMBER 66 WINTER 2012 Pages 17-19.

\title{
West African Higher Education Reforms
}

Juma Shabani

Juma Shabani is director of the UNESCO Bamako Cluster Office, Mali. E-mail: j.shabani@unesco.org.

Since the advent of the knowledge economy society, higher education is seen as a major contributor to poverty reduction and sustainable human development. Over the past two decades, many regional organizations have invested in the revitalization and further development of their higher education systems-in order to benefit from the opportunities offered by the knowledge economy. These efforts include the implementation of the Bologna process of construction of a higher education area in Europe and beyond by 2010 and the Higher Education Harmonization Strategy in Africa designed by the African Union. These two initiatives are mainly motivated by the need to move to a new system known as the bachelor-master-doctorate system.

The bachelor-master-doctorate reform does not aim at establishing a unique higher education system. In fact, the various national systems will be placed in a common framework of comparable and compatible qualifications, in order to promote and further strengthen academic and professional mobility. The Bologna process is a major reform of higher education in the participating countries. In France, for example, this process is considered as the most significant higher education reform since 1968.

Given their historical relations with Europe in the area of higher education, the African Francophone countries have taken steps since the mid-2000s to implement the 
bachelor-master-doctorate reforms, in order to maintain and further strengthen their academic and research cooperation with European countries.

In the West African Economic and Monetary Union (WAEMU), made up of eight Francophone and Lusophone countries (Benin, Burkina Faso, Côte d'Ivoire, Mali, Niger, Senegal, Togo, and Guinea Bissau), the bachelor-master-doctorate system was adopted by the ministers of higher education in July 2007 to achieve the following objectives: to improve the efficiency and performance of higher education institutions; to ensure international recognition of degrees issued in the WAEMU member states; and to promote students and staff mobility.

\section{THE BACHELOR-MASTER-DOCTORATE REFORM}

The implementation of the bachelor-master-doctorate reform in the WAEMU-member countries is considered an important step toward the construction of the African higher education and research space initiated by the African Union.

The main features of the bachelor-master-doctorate reform in Africa include the adoption of higher education systems made up of the three internationally recognized cycles of bachelor, master, and doctorate; the setting up of national qualifications frameworks, which will eventually lead to subregional and regional frameworks; and the division of periods of training in semesters and the adoption of two instruments that will facilitate comparability of qualifications and encourage academic mobility. These are the credit transfer system and the diploma supplement.

The implementation of the bachelor-master-doctorate reform in the WAEMUmember countries takes place at four levels: institutional, national, subregional, and 
African regional levels. At the African regional level, implementation of the bachelormaster-doctorate reform is coordinated by the African and Malagasy Council for Higher Education made up of 17 countries that include all the 8 WAEMU-member countries. Despite the progress made, implementation of this reform is still facing several challenges.

\section{CHALLENGES OF IMPLEMENTATION}

Implementation of the bachelor-master-doctorate reform in the WAEMU-member countries is facing three major challenges related to the quality of teaching and learning and the relevance of academic and research programs; the low level of research development; and the lack of credible mechanism for monitoring the credit-transfer systems. These challenges have been widely documented in recent publications on higher education in African Francophone countries.

\section{OPPORTUNITIES}

In recent years there has been a renewed interest for African member states and the donors' community to support the revitalization and further development of higher education and research in Africa. Indeed, almost every regional economic community in Africa has identified higher education as a major area for reform. The importance of higher education in Africa was reaffirmed at the 2009 World Conference on Higher Education and recent summits of African Union Heads of States and Governments. The first opportunity is, thus, provided by the priority given by the African Union to the development of higher education and the way it reflects in the various cooperation 
agreements recently signed between the African Union and developed and emerging countries. The second opportunity is related to the increased access to virtual infrastructures and the third opportunity is offered by the lessons that the WAEMUmember countries may learn from the Bologna process and adapt it to fit the African context, cultures, and values.

Based on several regional and interregional consultations, the WAEMU-member countries have developed, with the assistance of UNESCO, a three-year-pilot project for implementation of the bachelor-master-doctorate reform for the period of 2011-2013. This project is based on the use of information and communications technologies to strengthen the capacity needed for effective implementation of the reform.

The project aims at achieving three broad results. The first result is related to upgrading information and communications technology physical infrastructure to widen access to broadband Internet. For this purpose the campuses of public and accredited private universities in the eight WAEMU countries will be equipped with fiber optic facilities and at least 200 computers with high-speed data connection. The second result is related to the establishment of a series of virtual infrastructures to improve quality of teaching, learning, and research and to strengthen capacity for effective academic management. These include a network of virtual libraries and digital repositories; a virtual institute for delivery of online courses; university Web portals, and an online credit transfer system.

The third-expected result is linked to strengthening capacities to ensure effective implementation of the bachelor-master-doctorate reform. These include capacity for effective teaching and learning in higher education; development of effective 
accreditation and quality-assurance mechanisms; and research-capacity development. The project also aims at integrating the WAEMU centers of excellence into regional and international research networks.

\section{CONCLUSION}

Since the mid-2000s, all the regional-economic communities in Africa are involved in the implementation of higher education harmonization processes based on the bachelor-master-doctorate reform. Today it is agreed that the WAEMU strategy, based on the use of information and communications technologies to build the capacity required for effective implementation of this reform could lead to meaningful and sustainable results and therefore should serve as a model for the other subregions. 